\title{
Effect of Milk Base and Starter Culture on Acidification, Texture, and Probiotic Cell Counts in Fermented Milk Processing
}

\author{
I. Sodini, ${ }^{\star}$ A. Lucas, ${ }^{\star}$ M. N. Oliveira,† F. Remeuf, ${ }^{*}$ and G. Corrieu* \\ *Unité Mixte de Recherche de Génie et Microbiologie des Procédés Alimentaires, \\ Institut National Agronomique de Paris Grignon/Institut National de la Recherche Agronomique, \\ 78850 Thiverval Grignon, France \\ †São Paulo University, Department of Biochemical and Pharmaceutical Technology, \\ Av Prof Lineu Prestes, 580, 05508-900, São Paulo, Brazil
}

\section{ABSTRACT}

In the present work, the compared effect of milk base and starter culture on acidification, texture, growth, and stability of probiotic bacteria in fermented milk processing, was studied. Two strains of probiotic bacteria were used, Lactobacillus acidophilus LA5 and $L$. rhamnosus LR35, with two starter cultures. One starter culture consisted only of Streptococcus thermophilus ST7 (single starter culture); the other was a yogurt mixed culture with $S$. thermophilus ST7 and L. bulgaricus LB12 (mixed starter culture). For the milk base preparation, four commercial dairy ingredients were tested (two milk protein concentrates and two casein hydrolysates). The resulting fermented milks were compared to those obtained with control milk (without enrichment) and milk added with skim milk powder. The performance of the two probiotic strains were opposite. L. acidophilus LA5 grew well on milk but showed a poor stability during storage. L. rhamnosus LR35 grew weakly on milk but was remarkably stable during storage. With the strains tested in this study, the use of the single starter culture and the addition of casein hydrolysate gave the best probiotic cell counts. The fermentation time was of about $11 \mathrm{~h}$, and the probiotic level after five weeks of storage was greater than $10^{6}$ $\mathrm{cfu} / \mathrm{ml}$ for L. acidophilus LA5 and $10^{7} \mathrm{cfu} / \mathrm{ml}$ for $L$. rhamnosus LR35. However, an optimization of the level of casein hydrolysate added to milk base has to be done, in order to improve texture and flavor when using this dairy ingredient.

(Key words: probiotic bacteria, dairy ingredients, stability, texture)

Abbreviation key: $\mathbf{M P C}=$ milk protein concentrate, $\mathbf{C H}=$ casein hydrolysate, $\mathbf{S S C}=$ single starter culture , $\mathbf{M S C}=$ mixed starter culture, $\mathbf{S M P}=$ skim milk powder .

Received December 6, 2001.

Accepted January 4, 2001.

Corresponding author: I. Sodini; e-mail: Sodini@grignon.inra.fr.

\section{INTRODUCTION}

Some strains of microorganisms have been used for a long time in animal feeding to improve their zootechnical performances. Over the last few decades, some strains of lactic acid bacteria belonging to bifidobacteria and lactobacilli have been introduced in food products for human consumption, with the aim to improve human health. They are called probiotic bacteria ("for life," in Greek) and are defined as living microorganisms, which upon ingestion in sufficient quantity, exert health benefits beyond inherent basic nutrition ( $\mathrm{Gu}-$ arner and Schaafsama, 1998). Fermented dairy products are the most widely used food vehicle for these bacteria, because dairy products have a healthy image. The first works reporting an effect on human health of the consumption of living bacteria have been criticized and subjected to a lot of controversies because of their lack of convenient design for experimentation. But these last years, a number of well-designed, randomized, and placebo-controlled double blind studies have been done. Some of them showed significant health effects of consumption of living bacteria, including certain strains of lactic acid bacteria as Lactobacillus rhamnosus GG, Lactobacillus casei Shirota, Lactobacillus acidophilus NCFB 1748, NCFM, LA5, or Lactobacillus johnsonii LA1 (Fonden et al., 2000).

A minimum level of living microorganisms is required to observe a positive effect of their consumption. For instance, a minimum daily dose of $10^{9} \mathrm{cfu} / \mathrm{d}$ of the strain L. johnsonii LA1 is required to modulate certain forms of nonspecific defense mechanisms. With the lower daily dose of $10^{8} \mathrm{cfu} / \mathrm{d}$, no significant effect on this function was reported (Donnet-Hughes et al., 1999). More generally, depending on the strains used and the required health effect, this level is usually between $10^{8}$ and $10^{11} \mathrm{cfu} / \mathrm{d}$ (Vanderhoof and Young, 1998). Therefore, assuming a daily consumption of fermented dairy products of $100 \mathrm{~g}$, they should contain between $10^{6} \mathrm{cfu} /$ $\mathrm{g}$ to $10^{9} \mathrm{cfu} / \mathrm{g}$ of these live bacteria at the time of consumption. This is often not the case in commercial products (Rybka and Fleet, 1997). The first reason for the 
low levels of probiotic bacteria observed in commercial products is the slow growth of the probiotic strains. They are not competitive with the strains of the starter culture. Secondly, they often have a poor stability during storage. For instance, a 3-log decrease after only 2 wk of storage at $4^{\circ} \mathrm{C}$ has been reported for the probiotic strain $L$. johnsonii LA1 in a fermented milk (Saxelin et al., 1999).

Several works have been done to improve the growth of probiotic bacteria by acting on milk base. The positive effect of adding nonproteic nitrogen (Saxena et al., 1994; Dave and Shah, 1998; Oliveira et al., 2002), oxygen scavengers (Dave and Shah, 1998; Shah, 2000), oligosaccharides (Shin et al., 2000), and sugar sources (Saxena et al., 1994), have been reported. For instance, with pure culture of probiotic lactobacilli, Saxena et al. (1994) and Oliveira et al. (2002) noticed than acidification rate was doubled by adding casitone $\left(5 \mathrm{~g} \cdot \mathrm{kg}^{-1}\right)$ or tryptone $\left(20 \mathrm{~g} \cdot \mathrm{L}^{-1}\right)$. Dave and Shah (1998), using a very small level of tryptone $\left(250 \mathrm{mg} \cdot \mathrm{L}^{-1}\right)$, increased by $3 \mathrm{log}$ the level of bifidobacteria in a fermented milk containing starter culture and probiotic bacteria. The same authors studied the effect of adding cystein as oxygen scavenger. With $500 \mathrm{mg} \cdot \mathrm{L}^{-1}$ of cystein, the growth of L. acidophilus was slightly better $\left(1.7 \times 10^{8}\right.$ versus 4.5 $\times 10^{7} \mathrm{cfu} / \mathrm{g}$ ), and one of the bifidobacteria was greatly improved $\left(4.0 \times 10^{5}\right.$ versus $\left.7.1 \times 10^{2} \mathrm{cfu} / \mathrm{g}\right)$. The effect of adding sugar can be positive up to a certain level. Saxena et al. (1994) observed a stimulation of $L$. acidophilus growth when $0.5 \%$ of fructose was added to milk (50\% increase for acidification rate in pure culture). On the other hand, with high addition level (12 to 16\%), Shah and Ravula (2000) noticed a growth inhibition for strains of L. acidophilus and bifidobacteria (1 and 2 log less in the final product for both strains, with 12 and $16 \%$, respectively, of sugar compared with $8 \%$ ). For bifidobacteria, it has been reported that milk supplementation with $5 \%$ of fructooligosaccharides can reduce the mean doubling time by almost twice (Shin et al., 2000). The choice of the starter culture seems also to have a positive or negative effect on probiotic growth, depending on involved protocooperation, inhibition, or competition phenomena (Dave and Shah, 1997; Saxelin et al., 1999). Dave and Shah (1997), with mixed cultures of starter and probiotic, noticed a probiotic generation number during fermentation comprised between 0.7 and 4 depending on the starter used. Furthermore, for one strain of bifidobacteria, these authors reported an antagonistic relationship with a starter strain, leading to a 3-log decrease of the bifidobacteria during fermentation.

After fermentation and formulation of the dairy product, the level of probiotic bacteria has to remain stable. It has been shown that the product composition as the content of total nonfat solids (Gardini et al., 1999), and the addition of sugar (Shah and Ravula, 2000), carbon dioxide (Vinderola et al., 2000b), and oligosaccharides (Shin et al., 2000) can have an effect on the stability of probiotic cells. Gardini et al. (1999) noticed a better survival of $L$. acidophilus during storage in milk with low total nonfat solids (10 versus $16 \%$ ). Vinderola et al. (2000b), studying the effect of $\mathrm{CO}_{2}$ on growth and viability of $L$. acidophilus cultured with bifidobacteria and starters, showed a significant lowering of $L$. acidophilus in carbonated fermented milk, by comparison to control. According Shah and Ravula (2000), with a sugar level of $12 \%$ instead of $8 \%$, the viability of probiotic cultures is lower (loss of 3 log instead of 2 log after $49 \mathrm{~d}$ of storage). For two strains of bifidobacteria, Shin et al. (2000) reported a better viability after $4 \mathrm{wk}$ of storage when milk is supplemented with $5 \%$ of fructooligosaccharides. They calculated a viability of 44 to $67 \%$ when milk is supplemented, instead of 9.3 to $11.6 \%$ for control. The activity of the starter culture during fermentation and storage is sometimes negative for the survival of the probiotic strain (Nighswonger et al., 1996; Dave and Shah, 1997; Rybka and Fleet, 1997; Saxelin et al., 1999; Godward et al., 2000). Dave and Shah (1997) compared four starter cultures used in combination with probiotic culture of $L$. acidophilus and bifidobacteria. For L. acidophilus, the decrease observed during 5 wk of storage was less pronounced (2 $\log$ versus $3 \log$ ) when the starter was devoid of $L$. bulgaricus. Saxelin et al. (1999), with seven strains of probiotic bacteria, reported a good stability during $2 \mathrm{wk}$ of storage for three of them, and a decrease comprised between 1 and $3 \log$ for the four other strains. In any case, the higher decreases were noticed with the starter containing L. bulgaricus. Nighswonger et al. (1996), comparing seven strains of probiotic lactobacilli, showed that the stability during 4 wk of storage was dependent on probiotic strain (decrease of 3 to $2 \mathrm{log}$ depending on the strain) and starter culture. For instance, with the strain $L$. acidophilus 0 - 16, the decrease was equal to $0.58 \mathrm{log}$ with one starter and to $1.37 \mathrm{log}$ with another.

Thus, milk base formulation and starter culture design seem to have strong effects on growth and stability of probiotic bacteria. The aim of this study was to compare these effects, in order to define the most accurate strategy to improve probiotic counts in fermented milk processing. As the manufacture of fermented milk also requires convenient acidification and texture, these characteristics were evaluated.

\section{MATERIALS AND METHODS}

\section{Strains and Dairy Ingredients}

Four commercial strains were used: Streptococcus thermophilus ST7 and Lactobacillus bulgaricus LB12 
Table 1. Nitrogen composition of the five dairy ingredients used for milk base formulation: one skim milk powder (SMP), two milk proteins concentrates (MPC1 and MPC2), and two casein hydrolysates (CH1 and CH2). Mean concentrations provided from two replicates are given in $\%(\mathrm{wt})$.

\begin{tabular}{lrrrrr}
\hline Nitrogen & SMP & MPC1 & MPC2 & CH1 & CH2 \\
\hline Total & 33.3 & 47.3 & 49.1 & 73.2 & 74.6 \\
Soluble & 7.3 & 17.1 & 9.6 & 73.2 & 71.1 \\
Nonproteic & 2.5 & 2.7 & 1.8 & 73.2 & 71.1 \\
\hline
\end{tabular}

for starter cultures, and Lactobacillus acidophilus LA5 and Lactobacillus rhamnosus LR35 for probiotic cultures (Chr. Hansen, Arpajon, France). Pure strain inocula were stored at $-70^{\circ} \mathrm{C}$ as concentrate. They were thawed and diluted 10 times in sterilized milk just before use.

Five dairy ingredients have been tested: a skim milk powder (SMP [Elle et Vire, Condé Sur Vire, France]), two milk protein concentrates (MPC1 and MPC2 [Promilk C500 A and Promilk C502; Ingredia, Arras, France]), and two casein hydrolysates (CH1 and $\mathrm{CH} 2$ [Vitalarmor 900LB; Armor Proteines, Saint Brice en Coglès, France, and Tryptone; Difco, Detroit, MI). Their nitrogen contents are reported in Table 1.

\section{Fermented Milk Preparation}

Commercial pasteurized low fat milk $\left(15 \mathrm{~g} \cdot \mathrm{L}^{-1}\right.$ of fat) and whole milk (36 $\mathrm{g} \cdot \mathrm{L}^{-1}$ of fat [Lactel; Lactalis, Laval, France]) were mixed to reach $26 \mathrm{~g} \cdot \mathrm{L}^{-1}$ of fat, and stan-

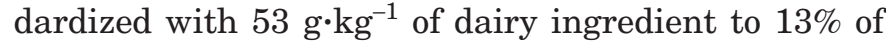
nonfat dry matter. Then it was submitted to thermal treatment at $92^{\circ} \mathrm{C}$ for $5 \mathrm{~min}$, cooled to $4^{\circ} \mathrm{C}$ in an iced bath, poured into 250-ml Erlenmeyer flasks, and stored $24 \mathrm{~h}$ before use. Milk with no added dairy ingredient was used as control.

The flasks were inoculated at the fermentation temperature with a probiotic culture (L. acidophilus LA5 or L. rhamnosus LR35) and a starter culture. Two starter cultures have been used: a single starter culture (SSC) composed only of $S$. thermophilus ST7, and a mixed starter culture (MSC) composed of S. thermophilus ST7 and $L$. bulgaricus LB12. The inoculation rates were equal to $0.01 \%$ for the probiotic culture and $0.02 \%$ for the starter culture. All inoculated milks were incubated at $40^{\circ} \mathrm{C}$ until $\mathrm{pH} 4.50$ was reached. Fermentation was stopped by rapidly cooling the fermented milk in an iced bath, manually stirring it with a stainless steel bored disk by up-and-down movements for almost 2 min, setting the stirred product into $100-\mathrm{ml}$ cups, and storing it at $4^{\circ} \mathrm{C}$.

Each of the 24 fermented milks studied ( 6 milk bases $\times 4$ cultures) was manufactured in four Erlenmeyer flasks, stirred, and poured at the end of fermentation into 10 cups. Four cups were used for the texture analysis, and six were kept for the microbiological analysis (one cup analyzed each week over $6 \mathrm{wk}$ ).

\section{Acidification Kinetics}

Acidification was studied for strains used in pure culture and during fermented milk preparation. Each fermentation, performed in four replicates, was monitored with the Cinac system (Corrieu et al., 1988), which allows a continuous recording of $\mathrm{pH}$. In the case of fermented milk preparation, fermentation time to reach $\mathrm{pH} 4.55$ was chosen as the endpoint to describe acidification. With the pure culture, it was not possible to reach $\mathrm{pH} 4.55$ for all the trials, especially for the one including streptococci. To be able to compare the pure cultures, fermentation time to reach $\mathrm{pH} 5$ was chosen as the endpoint of the fermentation.

\section{Texture Analysis}

In order to compare the texture of the fermented milks, two different textural properties were evaluated by using instrumental methods. The measurements were performed three times, after 2 wk of storage at $4^{\circ} \mathrm{C}$.

Rheological behavior. The rheological parameters were determined at $10^{\circ} \mathrm{C}$, by means of a stress-controlled rheometer model RS1 (Haake, Karlsruhe, Germany), used in harmonic and stationary mode. The rheometer was equipped with a $60-\mathrm{mm}$ diameter cone and plate geometry, with a $2^{\circ}$ angle cone and a $117-\mu \mathrm{m}$ gap. The fermented milk was gently mixed by stirring five times because some phase separation possibly occurred during storage, and $5 \mathrm{ml}$ were deposited on the plate of the rheometer by means of a syringe. The use of the syringe has been proved to avoid the presence of grains in the sampled material, which greatly disturb the measurement. Measurements in dynamic mode were carried out using a shear stress of $0.14 \mathrm{~Pa}$ at an oscillatory frequency of $1 \mathrm{~Hz}$ for $1 \mathrm{~min}$. The complex viscosity, in $\mathrm{Pa} \cdot \mathrm{s}$, was calculated by the determination of the mean of the 20 measures done during the analysis. Measurements in stationary mode were realized by applying a shear rate of $10 \mathrm{~s}^{-1}$. The apparent viscosity was determined after $3 \mathrm{~min}$ of shearing.

Graininess evaluation. The determination of the number of grains was made by an automatic image analysis procedure. One sample of fermented milk (1 g) was diluted in $10 \mathrm{ml}$ of distilled water, then poured in a Petri dish placed on an illuminated plate. The diluted sample was visualized by a digital color camera (JAI M2040; Imasys, Soresnes, France) equipped with an optical zoom. The image analysis was performed in 
grey level mode with commercial software (Optimas 6.2; Optimas Corporation, Silver Spring, MD). The grains having a perimeter higher than $1 \mathrm{~mm}$ were enumerated. The results are given by the number of grains per gram of fermented milk.

\section{Microbiological Analyses}

Cell count enumeration. For each run, fermented milks were analyzed each week during a 5 -wk storage at $4^{\circ} \mathrm{C}$. The first analysis (wk 0) was done just after fermentation at $\mathrm{pH}$ 4.50. Fermented milk samples were diluted in sterile tryptone diluent $(0.1 \% \mathrm{wt} / \mathrm{vol})$ and subsequently plated in duplicate onto selective media. The strain of L. acidophilus was enumerated according to IDF (1995) on MRS media (Biokar) added with 1.5 $\mathrm{g} / \mathrm{L}$ of bile (Biokar). The strain L. rhamnosus LR35 was enumerated according to Saxelin et al. (1999) on MRS media added with $50 \mathrm{mg} / \mathrm{L}$ of vancomycin (Sigma, St. Louis, MO). S. thermophilus and L. bulgaricus were enumerated on M17 media (Biokar) and MRS, respectively, at $\mathrm{pH}$ 5.4. The plate's incubation was done at $37^{\circ} \mathrm{C}$ for $72 \mathrm{~h}$, in an anaerobic jar containing GENbox (bioMérieux, Lyon, France) for all lactobacilli.

Generation number calculation. The generation number of probiotic during fermentation was determined from cfu enumeration by calculating the number of doublings between the beginning and the end of the fermentation.

\section{Statistical Analyses}

Results were submitted to ANOVA procedures using SAS Software (SAS Institute Inc., Cary, NC). For each main effect, a multiple comparison of means was performed, using the Bonferroni test $(P<0.05)$

\section{RESULTS}

\section{Acidification}

As a preliminary study, the effect of the dairy ingredients added for milk base preparation was studied with the strains used in pure culture. The results are reported in Figure 1. The strain L. rhamnosus LR35 grew poorly in milk, whatever the milk base. This observation was confirmed by a statistical analysis, comprising an ANOVA and a multiple comparison of means (data not shown). It showed that fermentation time was significantly higher for L. rhamnosus LR35 than for the three other strains, with a mean value equal to $23.5 \mathrm{~h}$ for this strain, by comparison to $11.4 \mathrm{~h}$ on average for the other three. The statistical analysis reported also that milk bases enriched with the three dairy ingredients, $\mathrm{CH} 2$, MPC1, and $\mathrm{CH} 1$ improved significantly the

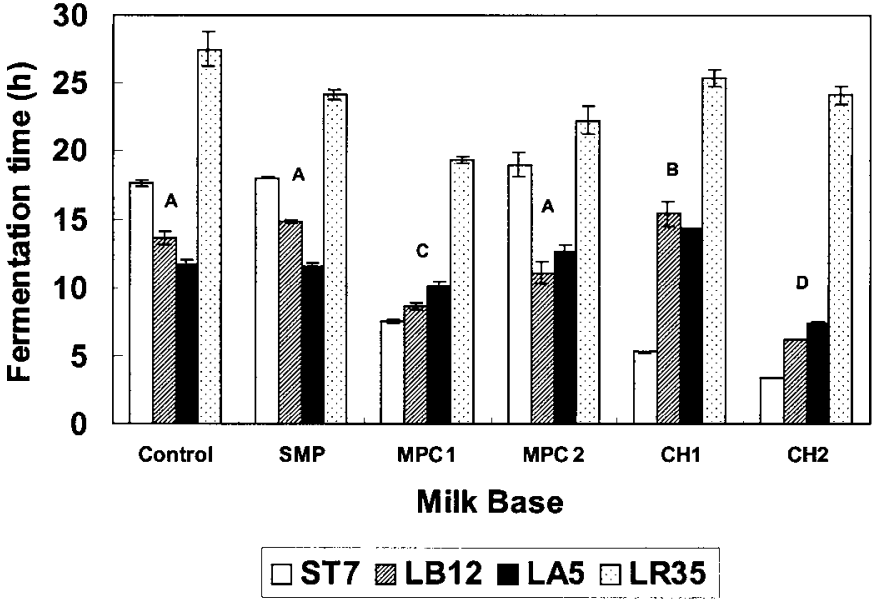

Figure 1. Effect of milk base on fermentation time required to reach $\mathrm{pH} 5$ for milk inoculated with a single culture of Streptococcus thermophilus ST7, Lactobacillus bulgaricus LB12, Lactobacillus acidophilus LA5, and Lactobacillus rhamnosus LR35. Milk base was not supplemented (control), or supplemented with skim milk powder (SMP), milk proteins (MPC1 and MPC2), and casein hydrolysates (CH1 and CH2). Milk bases with no common letter differ according to the Bonferroni test $(P \leq 0.05)$.

growth of the strains in pure culture. The mean fermentation times were equal to $10.2 \mathrm{~h}, 11.4 \mathrm{~h}$, and $15.1 \mathrm{~h}$ for milk bases containing $\mathrm{CH} 2$, MPC1, and $\mathrm{CH} 1$, respectively, by comparison to $16.5 \mathrm{~h}$ on average for the other milk bases. A significant interaction between the milk base and the inoculated strain was noticed $(P<0.01)$. The strain $S$. thermophilus ST7 was more stimulated than the other strains by the addition of dairy ingredient, with a fermentation time divided by three when the milk base was added with MPC1, $\mathrm{CH} 1$, or $\mathrm{CH} 2$, by comparison with the control. For the other strains, the supplementation divided the fermentation time by two, at most.

The fermentation times observed during fermented milk preparation are reported in Figure 2. The starter culture had a great effect on acidification, as fermentation time was, on average, divided by two and three for fermented milk containing $L$. acidophilus LA5 or $L$. rhamnosus LR35, respectively, when the MSC was used instead of the SSC. When the SSC is used, the dairy ingredient added for milk base had a strong effect on fermentation time, with the shortest fermentation time obtained with $\mathrm{CH} 2$, and the longest fermentation time obtained with MPC2. The values were, respectively, 5.1 $\mathrm{h}$ and $13.2 \mathrm{~h}$ for L. acidophilus LA5, and $6.1 \mathrm{~h}$ and $24 \mathrm{~h}$ for L. rhamnosus LR35. With the MSC, the milk base had a less important effect than with the SCC. For example, for the strain $L$. rhamnosus LR35, the fermentation time ranged between 4.1 and $7.2 \mathrm{~h}$ when the 
LA5

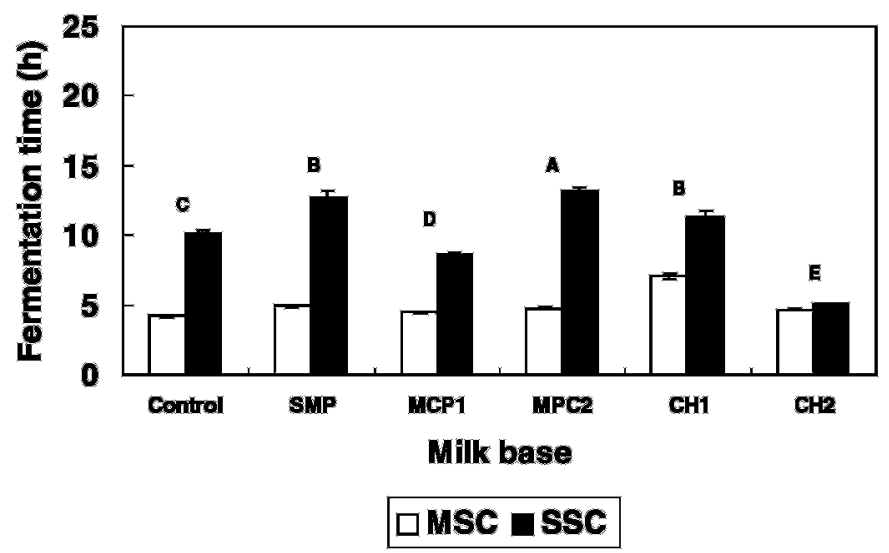

\section{LR35}

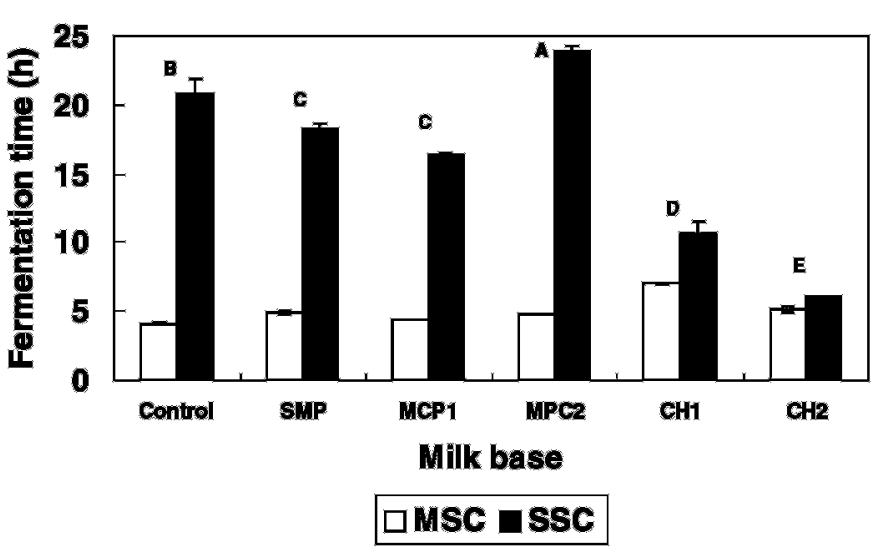

Figure 2. Effect of starter culture ${ }^{1}$ and milk base ${ }^{2}$ on fermentation time required to reach $\mathrm{pH} 4.55$ for milk inoculated with a mixed culture containing Lactobacillus acidophilus LA5 or Lactobacillus rhamnosus LR35. ${ }^{1}$ Starter culture was a mixed culture of Streptococcus thermophilus ST7 and Lactobacillus bulgaricus LB12 (MSC) or a single culture of $S$. thermophilus ST7 (SSC). ${ }^{2}$ Milk base was not supplemented (control), or supplemented with skim milk powder (SMP), milk proteins (MPC1 and MPC2), and casein hydrolysates (CH1 and CH2). Milk bases with no common letter differ according to the Bonferroni test $(P \leq 0.05)$.

MSC was used, while it varied from 6.1 to $24 \mathrm{~h}$ with the SSC.

\section{Texture}

The rheological parameters obtained for the fermented milks are given in Figures 3 and 4, showing, respectively, the complex and apparent viscosities. The same results were observed for these two different instrumental descriptors of the texture. The starter culture had a significant effect on rheological parameters, with the higher value obtained with the SSC. The milk
LA5

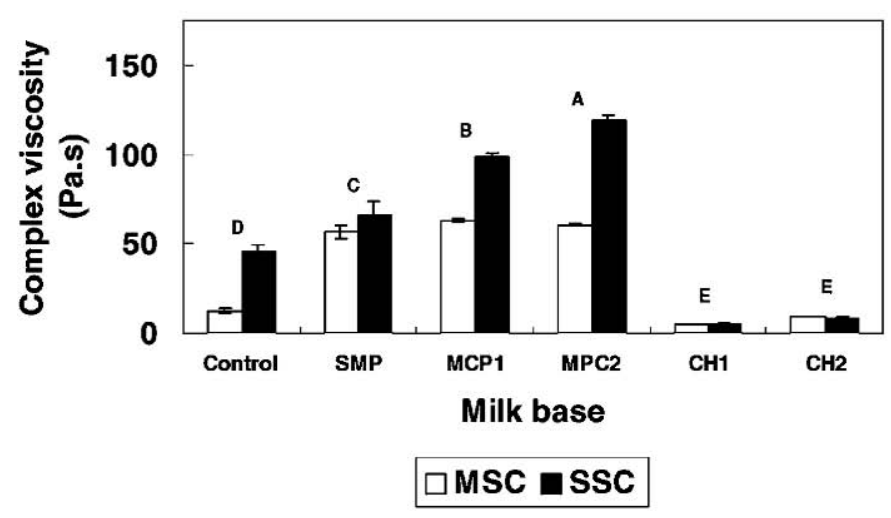

LR35

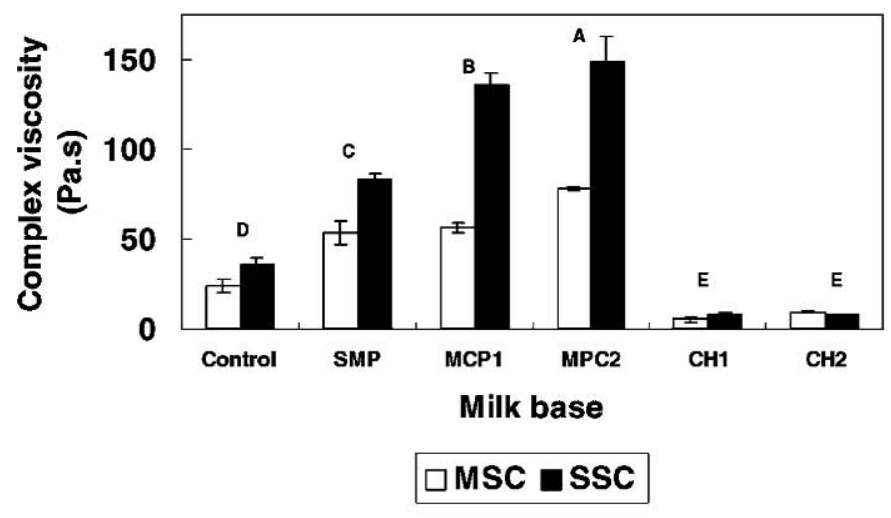

Figure 3. Effect of starter culture ${ }^{1}$ and milk base ${ }^{2}$ on complex viscosity of a fermented milk containing Lactobacillus acidophilus LA5 or Lactobacillus rhamnosus LR35. ${ }^{1}$ Starter culture was a mixed culture of Streptococcus thermophilus ST7 and Lactobacillus bulgaricus LB12 (MSC) or a single culture of $S$. thermophilus ST7 (SSC). ${ }^{2}$ Milk was not supplemented (control), or supplemented with skim milk powder (SMP), milk proteins (MP1 and MP2), and casein hydrolyzates ( $\mathrm{CH} 1$ and $\mathrm{CH} 2)$. Milk bases with no common letter differ according to the Bonferroni test $(P \leq 0.05)$.

base had also a significant effect on texture, with the lowest values obtained when $\mathrm{CH} 1$ or $\mathrm{CH} 2$ were added, and the highest values obtained with MPC1 and MPC2 (slightly higher for MPC2 than for MPC1 for complex viscosity; see Figure 3). Actually, a lack of convenient coagulation was observed at $\mathrm{pH} 4.5$ when $\mathrm{CH} 1$ or $\mathrm{CH} 2$ were added to the milk base, which explains the very low values of complex and apparent viscosities reported (less than 10 Pa.s, and $1 \mathrm{~Pa} . \mathrm{s}$, respectively, by comparison with 54 to $142 \mathrm{~Pa} . \mathrm{s}$, and 3 to $6 \mathrm{~Pa}$.s for the other milk bases). The interaction between the starter culture and the milk base was once more highly significant $(P$ $<0.01$ ). The effect of milk base on texture was higher when the SSC was used. For instance, the increase 
LA5

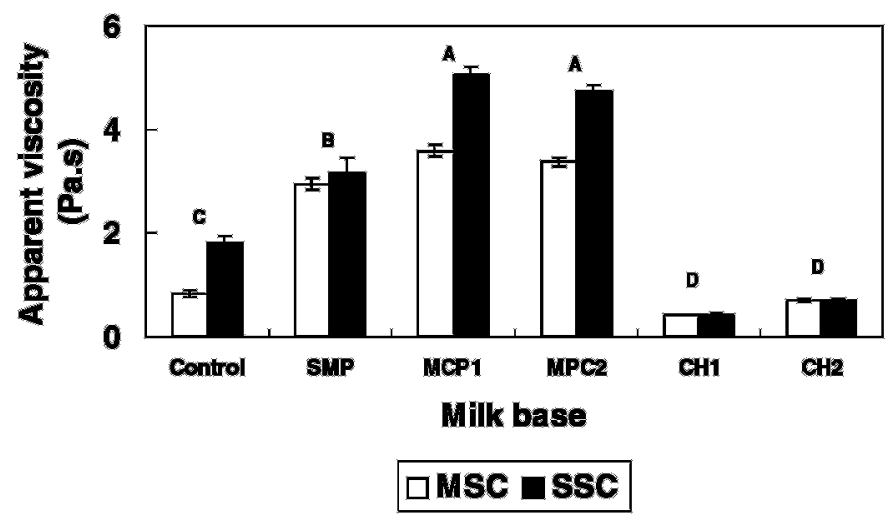

LR35

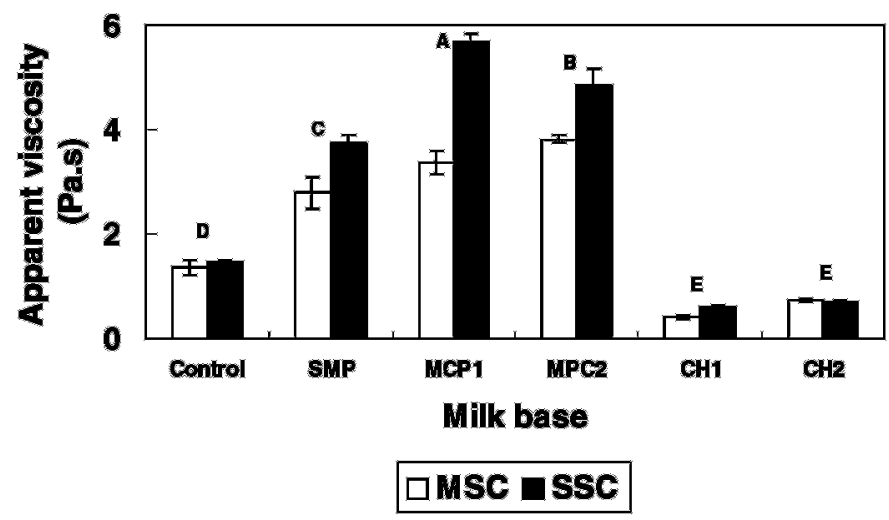

Figure 4. Effect of starter culture ${ }^{1}$ and milk base ${ }^{2}$ on apparent viscosity at $10 \mathrm{~s}^{-1}$ of fermented milk containing Lactobacillus acidophilus LA5 or Lactobacillus rhamnosus LR35. ${ }^{1}$ Starter culture was a mixed culture of Streptococcus thermophilus ST7 and Lactobacillus bulgaricus LB12 (MSC) or a single culture of S. thermophilus ST7 (SSC). ${ }^{2}$ Milk base was not supplemented (control), or supplemented with skim milk powder (SMP), milk proteins (MPC1 and MPC2), and casein hydrolysates ( $\mathrm{CH} 1$ and $\mathrm{CH} 2)$. Milk bases with no common letter differ according to the Bonferroni test $(P \leq 0.05)$.

of complex viscosity observed between the fermented milks containing the strain L. rhamnosus LR35 and coming from a milk without supplementation (control) or added with MPC2, was equal to $130 \%$ and $280 \%$, respectively, with the MSC and the SSC.

In the case of a milk base supplemented with $\mathrm{CH} 1$ and $\mathrm{CH} 2$, which did not coagulate, the fermented milks were smooth and without any grains. For the other milk bases, whatever the probiotic strain used, the graininess of the fermented milks was negligible (number of grains per gram less than 10) when the MSC was used and high (number of grains per gram was between 40 and 120) with the SSC (data not shown).
LA5
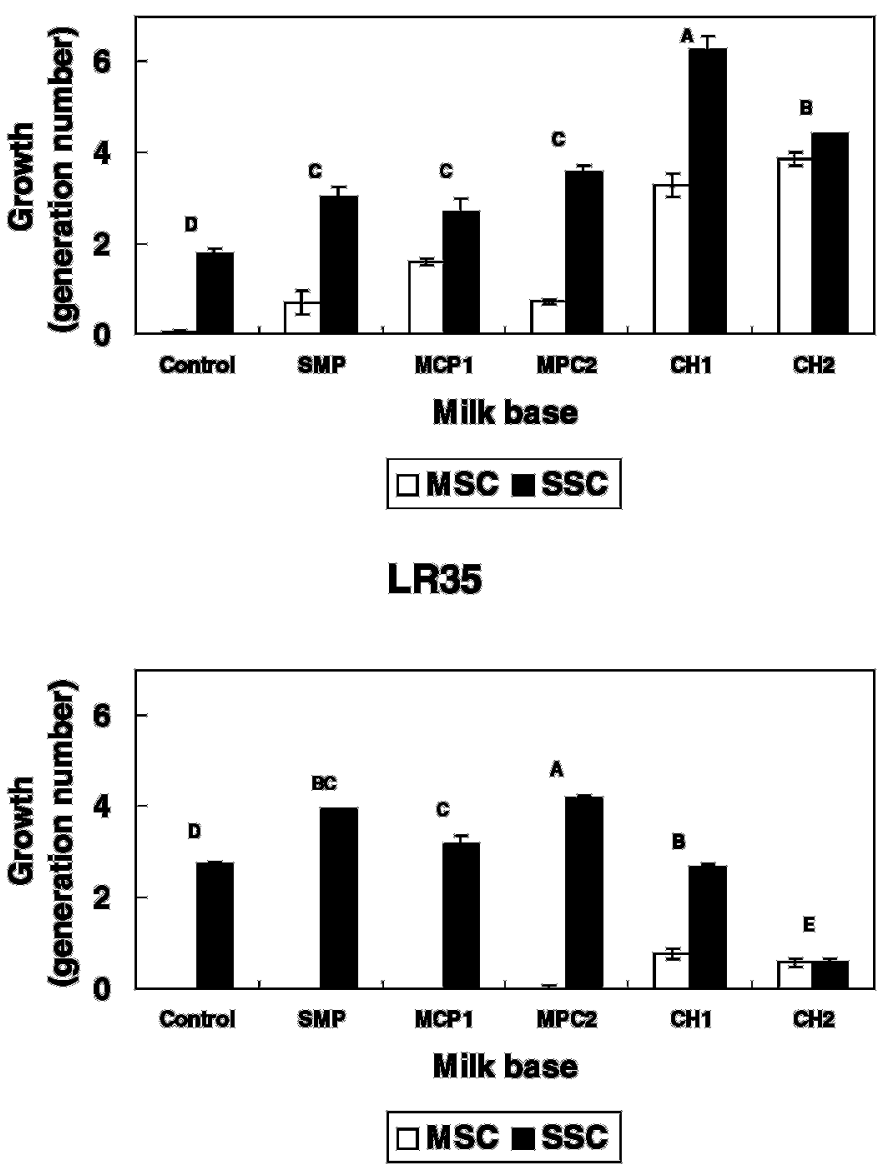

Figure 5. Effect of starter culture ${ }^{1}$ and milk base ${ }^{2}$ on growth expressed in generation number of Lactobacillus acidophilus LA5 or Lactobacillus rhamnosus LR35. ${ }^{1}$ Starter culture was a mixed culture of Streptococcus thermophilus ST7 and Lactobacillus bulgaricus LB12 (MSC) or a single culture of $S$. thermophilus ST7 (SSC). ${ }^{2}$ Milk base was not supplemented (control), or supplemented with skim milk powder (SMP), milk proteins (MPC1 and MPC2), and casein hydrolysates (CH1 and $\mathrm{CH} 2)$. Milk bases with no common letter differ according to the Bonferroni test $(P \leq 0.05)$.

\section{Probiotic Growth}

To calculate the probiotic growth during fermentation, the generation number between the beginning and the end of the process was considered. The results are reported in Figure 5. It was between 0 and 6.3 depending on probiotic strain, starter culture, and milk base. It was on average higher for L. acidophilus LA5 than for L. rhamnosus LR35. The effect of starter culture and milk base was studied by an ANOVA. The effect of starter culture was highly significant $(P<0.01)$, with higher generation numbers when the SSC was used, instead of the MSC ( 0.6 to 6.3 versus 0 to 3.9 ). The effect of milk base was also highly significant $(P<$ 
Table 2. Effect of starter culture ${ }^{1}$ and milk base $^{2}$ on the concentration of Lactobacillus acidophilus LA5 in fermented milk over a storage period of $5 \mathrm{wk}$ at $4^{\circ} \mathrm{C}$. Means are calculated from two duplicates. The comparison between the six milk bases (data in columns) and the six storage periods (data in rows) has been done by a multiple comparison of means using the Bonferroni test (see left and right superscripts, respectively).

\begin{tabular}{|c|c|c|c|c|c|c|c|}
\hline \multirow{2}{*}{$\begin{array}{l}\text { Starter } \\
\text { culture }\end{array}$} & \multirow{2}{*}{$\begin{array}{l}\text { Milk } \\
\text { base }\end{array}$} & \multicolumn{6}{|c|}{ Storage period (wk) } \\
\hline & & 0 & 1 & 2 & 3 & 4 & 5 \\
\hline \multirow[t]{2}{*}{ MSC } & 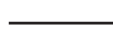 & 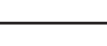 & $-\left(\log _{10}\right.$ & L) & 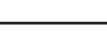 & - & \\
\hline & $\begin{array}{l}\text { Control } \\
\text { SMP } \\
\text { MPC1 } \\
\text { MPC2 } \\
\text { CH1 } \\
\text { CH2 }\end{array}$ & $\begin{array}{c}{ }^{\mathrm{c}} 6.85^{\mathrm{A}} \\
{ }^{\mathrm{c}} 7.05^{\mathrm{A}} \\
{ }^{\mathrm{b}} 7.33^{\mathrm{A}} \\
{ }^{\mathrm{c}} 7.06^{\mathrm{A}} \\
{ }^{\mathrm{a}} 7.83^{\mathrm{A}} \\
{ }^{\mathrm{a}} 8.01^{\mathrm{A}}\end{array}$ & $\begin{array}{c}{ }^{\mathrm{a}} 6.64^{\mathrm{A}} \\
{ }^{\mathrm{a}} 7.02^{\mathrm{A}} \\
{ }^{\mathrm{a}} 7.04^{\mathrm{A}} \\
{ }^{\mathrm{a}} 7.02^{\mathrm{A}} \\
\mathrm{ND}^{3} \\
{ }^{\mathrm{a}} 6.87^{\mathrm{B}}\end{array}$ & $\begin{array}{l}{ }^{\mathrm{b}} 6.07^{\mathrm{B}} \\
{ }^{\mathrm{c}} 5.37^{\mathrm{B}} \\
{ }^{\mathrm{d}} 4.15^{\mathrm{B}} \\
{ }^{\mathrm{c}} 5.30^{\mathrm{B}} \\
{ }^{\mathrm{a}} 6.77^{\mathrm{B}} \\
{ }^{\mathrm{c}} 4.93^{\mathrm{C}}\end{array}$ & $\begin{array}{l}<3.50 \\
<3.50 \\
{ }^{\mathrm{a}} 4.37^{\mathrm{B}} \\
<3.50 \\
{ }^{\mathrm{a}} 4.43^{\mathrm{C}} \\
{ }^{\mathrm{b}} 3.76^{\mathrm{D}}\end{array}$ & $\begin{array}{c}<3.50 \\
<3.50 \\
<3.50 \\
<3.50 \\
<3.50 \\
3.72^{\mathrm{D}}\end{array}$ & $\begin{array}{l}<3.50 \\
<3.50 \\
<3.50 \\
<3.50 \\
<3.50 \\
<3.50\end{array}$ \\
\hline \multirow[t]{2}{*}{$\mathrm{SSC}$} & & & $-\left(\log _{10}\right.$ & L) & & & \\
\hline & $\begin{array}{l}\text { Control } \\
\text { SMP } \\
\text { MPC1 } \\
\text { MPC2 } \\
\text { CH1 } \\
\text { CH2 }\end{array}$ & $\begin{array}{r}\mathrm{d} 7.38^{\mathrm{A}} \\
\mathrm{cd} 7.75^{\mathrm{A}} \\
\mathrm{cd} 7.66^{\mathrm{A}} \\
\mathrm{bc} 7.91^{\mathrm{A}} \\
{ }^{\mathrm{a}} 8.73^{\mathrm{A}} \\
{ }^{\mathrm{b}} 8.17^{\mathrm{A}}\end{array}$ & $\begin{array}{r}{ }^{\mathrm{d}} 6.49^{\mathrm{B}} \\
\text { bc } 7.84^{\mathrm{A}} \\
{ }^{\mathrm{b}} 7.99^{\mathrm{A}} \\
{ }^{\mathrm{c}} 7.53^{\mathrm{A}} \\
{ }^{\mathrm{a}} 8.66^{\mathrm{A}} \\
{ }^{\mathrm{c}} 7.55^{\mathrm{B}}\end{array}$ & $\begin{array}{l}{ }^{\mathrm{d}} 3.84^{\mathrm{C}} \\
\mathrm{b}^{\mathrm{b}} 6.53^{\mathrm{B}} \\
{ }^{\mathrm{c}} 4.50^{\mathrm{B}} \\
{ }^{\mathrm{c}} 5.08^{\mathrm{B}} \\
{ }^{\mathrm{a}} 8.69^{\mathrm{A}} \\
{ }^{\mathrm{b}} 6.81 \mathrm{C}\end{array}$ & $\begin{array}{l}<3.50 \\
{ }^{\mathrm{c}} 4.47^{\mathrm{C}} \\
{ }^{\mathrm{c}} 4.47^{\mathrm{B}} \\
{ }^{\mathrm{d}} 4.10^{\mathrm{C}} \\
{ }^{\mathrm{a}} 7.08^{\mathrm{B}} \\
{ }^{\mathrm{b}} 6.01^{\mathrm{D}}\end{array}$ & $\begin{array}{l}<3.50 \\
<3.50 \\
<3.50 \\
{ }^{\mathrm{c}} 3.83^{\mathrm{C}} \\
{ }^{\mathrm{a}} 6.50^{\mathrm{C}} \\
{ }^{\mathrm{b}} 5.73^{\mathrm{D}}\end{array}$ & $\begin{array}{l}<3.50 \\
<3.50 \\
<3.50 \\
<3.50 \\
{ }^{\mathrm{a}} 6.31^{\mathrm{C}} \\
{ }^{\mathrm{b}} 5.13^{\mathrm{E}}\end{array}$ \\
\hline
\end{tabular}

\footnotetext{
${ }^{1}$ Starter culture was a mixed culture of Streptococcus thermophilus ST7 and Lactobacillus bulgaricus LB12 (MSC) or a pure culture of Streptococcus thermophilus ST7 (SSC).

${ }^{2}$ Milk base was not supplemented (control), or supplemented with skim milk powder (SMP), milk protein concentrates (MPC1 and MPC2), and casein hydrolysates (CH1 and CH2).

${ }^{3}$ Not determined.

a, b, c, dColumn means with no common superscripts differ $(P \leq 0.05)$.

A, B, C, D, E Row means with no common superscripts differ $(P \leq 0.05)$.
}

0.01). Their ability to stimulate probiotic growth depended on the strain. For L acidophilus LA5, the CH permitted the highest growth (generation number equal to 4 on average). For L. rhamnosus LR35, the dairy ingredients MPC2 and CH1 were the most stimulating for the growth of the probiotic (generation number equal to 2 on average). There was a significant interaction between the starter culture and the milk base. For instance, the $\mathrm{CH}$ had a positive effect on growth of $L$. rhamnosus LR35 when performed with the MSC, but a negative effect when cultured with the SSC.

\section{Probiotic Stability}

The concentration of probiotic bacteria $L$. acidophilus LA5 and L. rhamnosus LR35 was followed for $5 \mathrm{wk}$, and is reported in Tables 2 and 3, respectively. The two probiotic strains did not show the same stability during storage. Whatever the starter culture and the milk base, $L$. acidophilus LA5 concentration decreased significantly during the 5 wk of storage, showing a lowering of at least $2 \log$ to more than $4.5 \mathrm{log}$. On the other hand, L. rhamnosus LR35 did not lower significantly for eight of the 12 conditions tested, and in any case, the lowering was less than $1 \mathrm{log}$. The effect of starter culture and milk base was not significant for the stability of this strain, which remained at a high concentration in fermented milk (higher than $10^{6} \mathrm{cfu} / \mathrm{ml}$ ). How- ever, the starter culture and the milk base influenced the concentration of $L$. acidophilus LA5. The better stability for this strain was observed with the SSC and the milk base enriched in $\mathrm{CH}$, which permitted it to maintain more than $10^{6} \mathrm{cfu} / \mathrm{ml}$ after $3 \mathrm{wk}$ of storage, and more than $10^{5} \mathrm{cfu} / \mathrm{ml}$ after $5 \mathrm{wk}$.

\section{DISCUSSION}

\section{Acidification}

The results obtained with the strains used in pure cultures underlined the poor ability of some strains of probiotic bacteria to grow on milk. For instance, Saxelin et al. (1999) reported for the strain $L$. paracasei F19 a poor milk acidification, with a fermentation time to reach $\mathrm{pH} 4.5$ of more than $20 \mathrm{~h}$. In our study, the strain L. rhamnosus LR35 took more than $20 \mathrm{~h}$ to reach $\mathrm{pH}$ 5.0. Saxelin et al. (1999) and Saxena et al. (1994) reported that the addition of nonproteic nitrogen such as yeast extract or $\mathrm{CH}$ could improve greatly the growth of some probiotic strains, as noticed here for strain LA5 with the addition of $\mathrm{CH} 2$. Anyway, the most pronounced effect of milk base supplementation was observed with the strain S. thermophilus ST7. This could be ascribed to the lower proteolytic activity of $S$. thermophilus than that of lactobacilli (Rajagopal and Sandine, 1990). Thus, S. thermophilus should be more sensitive to incor- 
Table 3. Effect of starter culture ${ }^{1}$ and milk base $^{2}$ on the concentration of Lactobacillus rhamnosus LR35 in fermented milk over a storage period of $5 \mathrm{wk}$ at $4^{\circ} \mathrm{C}$. Means are calculated from two duplicates. The comparison between the six milk bases (data in columns) and the six storage periods (data in rows) has been done by a multiple comparison of means using the Bonferroni test (see left and right superscripts, respectively).

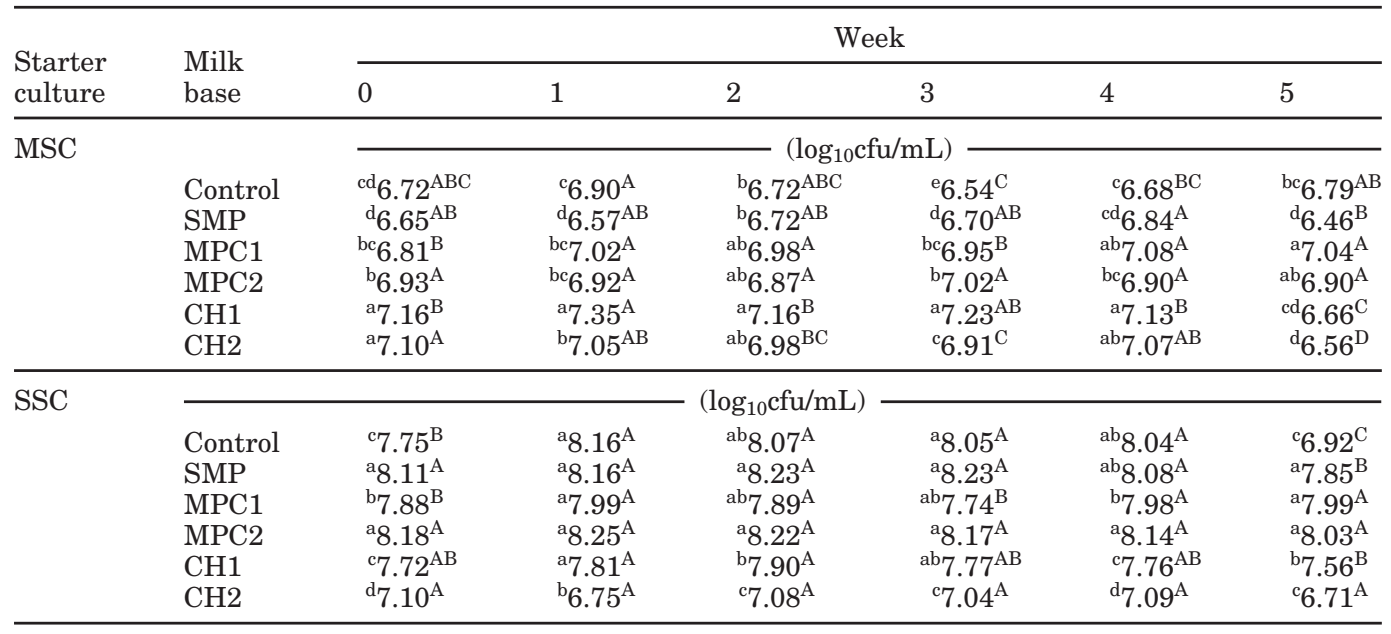

${ }^{1}$ Starter culture was a mixed culture of Streptococcus thermophilus ST7 and Lactobacillus bulgaricus LB12 (MSC) or a single culture of Streptococcus thermophilus ST7 (SSC).

${ }^{2}$ Milk base was not supplemented (control), or supplemented with skim milk powder (SMP), milk protein concentrates (MPC1 and MPC2), and casein hydrolysates (CH1 and $\mathrm{CH} 2$ ).

a, b, c, dColumn means with no common superscripts differ $(P \leq 0.05)$.

A, B, C, D Row means with no common superscripts differ $(P \leq 0.05)$.

poration of potential nitrogen sources brought by dairy ingredients.

The acidification of the fermented milks is strongly related to the composition of the starter culture. The MSC, composed of S. thermophilus ST7 and L. bulgaricus LB12, presented a high interaction factor (Sodini et al., 2000) and permitted a short fermentation time. Similar results were reported by Kneifel et al. (1993), and Dave and Shah (1997), who observed a decrease in the fermentation time of 20 to $50 \%$ when the MSC was used instead of a SSC, as compared with 50 to $70 \%$ reduction in our case.

The effect of milk base can be partially explained by the nitrogen composition of the added dairy ingredients reported in Table 1. The $\mathrm{CH} 2$, which gave the lowest fermentation time, contained a high level of nonproteic nitrogen (more than 70\%), as compared with MPC2 (less than 2\%). Besides, the fermentation is not only related to the nonproteic content of the dairy ingredient, because the $\mathrm{CH} 1$, which had the same level of nonproteic content than the $\mathrm{CH} 2$, did not give the same results. The composition of the nonproteic fraction (content in free amino acids and peptides) should also influence its ability to stimulate bacteria growth.

\section{Texture}

The texture was influenced strongly by the starter culture and the milk base. The graininess of fermented milks, which is higher with the SSC than with the MSC, might be related to the long fermentation time (more than $10 \mathrm{~h}$ ). It increases the phenomena of coagulation in two steps as described by Lucey and Singh (1998). According to these authors, in a milk base increasingly heated, the aggregation would be expected to start at $\mathrm{pH} 5.3$, which is the isoelectric $\mathrm{pH}$ of the $\beta$-lactoglobulin, and would continue until $\mathrm{pH} 4.6$, which is the isoelectric $\mathrm{pH}$ of the casein. Possibly, some bonds would be broken during this two-step coagulation, when the casein network begins to be built. It should favor grain formation. If the fermentation time is long, the elapsed time between these two $\mathrm{pH}$ levels is also long. The number of bonds created during the first stage of coagulation is then higher, so the number of bonds broken is also higher during the second stage, thus leading to an increase of the number of grains at the end of coagulation. The cross-linking density of the matrix, as assessed by viscosity measurements, has been shown to be higher with a slow acidification (Van Marle and Zoon, 1995; Beal et al., 1999), which could explain the generally higher rheological parameters obtained with the SSC (10 to $15 \mathrm{~h}$ for fermentation time) than with the MSC (5 h).

The addition of dairy ingredients, which increases the DM content, increased the rheological parameters, except for the $\mathrm{CH}$, which gave products without thickness and with poor viscosity. This effect of $\mathrm{CH}$ on fer- 
mented milk texture has already been noticed by Saxena et al. (1994). It is possible that the $\mathrm{CH}$, rich in nonproteic material as amino acids or peptides, have a masking effect on milk proteins, hindering the network formation. For the other dairy ingredients, their texturing capacity was directly related to their protein content. It was higher for MPC than for milk powder, with values equal respectively to $30.9,44.6$, and $47.3 \%$ for SMP, MPC1, and MPC2, thus giving a final protein content in milk base of $4.66,5.35$, and $5.49 \%$. The positive relationship between the milk base protein content and the yogurt texture has been emphasized by other authors (Rohm and Schmidt, 1993; Lankes et al., 1998).

\section{Probiotic Growth}

The probiotic lactobacilli growth during fermentation was generally between 2 and 4 generation number, which is comparable to several values reported in literature, for example 1.3 for Shah and Ravula (2000) and 1 to 3 for Dave and Shah (1997). It was clear that the starter culture chosen had an important effect, and a better growth was observed with the SSC. This effect can be due to a phenomena of competition between the lactobacilli, which could slow the growth of the probiotic lactobacilli when they are cultured with the yogurt one, L. bulgaricus. However, these results were in contradiction with those reported by Dave and Shah (1997), who observed no difference between an SSC and an MSC for the growth of strains of L. acidophilus.

The milk base had an effect on probiotic growth, as noticed by Dave and Shah (1998), who reported also a high growth when milk was supplemented with $\mathrm{CH}$. This was probably due to the nonproteic nitrogen of the hydrolysate which can stimulate the weakly proteolytic probiotic strains (Shihata and Shah, 2000).

\section{Probiotic Stability}

The stabilities of the two strains tested in this study were very different. For L. rhamnosus LR35, the decrease in count was less than $1 \log$ in $6 \mathrm{wk}$, which was comparable to the results obtained by Gardini et al. (1999) with L. acidophilus IPVR 224 and by Vinderola et al. (2000b) with $L$. acidophilus LaA3 (decrease of, respectively, $1.7 \log$ in $5 \mathrm{wk}$, and $0.5 \log$ in $7 \mathrm{wk}$ ). For the strain L. acidophilus LA5, under the applied experimental conditions, the decrease was much higher, between 2 and $4.5 \mathrm{log}$ after 5 wk of storage, comparable to other strains studied in the literature. For example, Saxelin et al. (1999) with the strain $L$. salivarius UCC118, and Vinderola et al. (2000a) with the strain L. acidophilus LA1, reported respectively a decrease of $3 \log$ in $2 \mathrm{wk}$, and 2.7 to $4.6 \log$ in 4 wk.
The starter culture had a significant effect on the stability of $L$. acidophilus LA5, which was reported for other strains (Dave and Shah, 1997; Saxelin et al., 1999; Vinderola et al., 2000a). Generally, the stability was better with the SSC, devoid of $L$. bulgaricus. The postacidification and the releasing of hydrogen peroxide caused by L. bulgaricus could decrease the stability of the probiotic strains. The works of Vinderola et al. (2000a) and Karagük-Yücer et al. (2000) have shown the sensitivity of probiotic strains to low $\mathrm{pH}$. In our study, the $\mathrm{pH}$ of all fermented milks was lowered during the storage period (data not shown), but the final $\mathrm{pH}$ after 5 wk of storage was more acidic for the ones containing $L$. bulgaricus (4.12 to 4.15 ) than for the ones which were devoid of this strain (4.24 to 4.25$)$. On the other hand, Dave and Shah (1997) have noticed a higher production of hydrogen peroxide with the starter culture containing $L$. bulgaricus and suspected it causes a partial injury to the cells of L. acidophilus. According to these authors, the partially injured cells might show faster decay in the viable cell counts in fermented milks.

The milk base has also an effect on probiotic stability, in the case of the strain L. acidophilus LA5. The milk base enriched with $\mathrm{CH}$ reduced the decrease of probiotic counts during storage. Similar results were obtained by Saxena et al. (1994) and Dave and Shah (1998), but they were poorly discussed. Possibly the presence of a fraction of nonproteic nitrogen allows a cellular activity during storage, thus slowing down the reduction of the viable cells.

\section{CONCLUSIONS}

This study has shown that the behavior of mixed probiotic cultures is different according to the criteria studied. For a fast acidification and a smooth texture, the best starter culture is the mixed one. For a significant probiotic growth and a high stability, the single one is the most convenient. In this case, the use of casein hydrolysate is useful to lower the fermentation time, and, in addition, it enhances the probiotic stability. The fermentation time is equal to $11 \mathrm{~h}$. After $5 \mathrm{wk}$ of storage, probiotic cell counts exceed $10^{6} \mathrm{cfu} / \mathrm{ml}$ for Lactobacillus acidophilus LA5, and $10^{7} \mathrm{cfu} / \mathrm{ml}$ for Lactobacillus rhamnosus LR35. However, a poor viscosity and a bitter flavor have been observed due to the high level of $\mathrm{CH}$ added. A lower level of $\mathrm{CH}$, or the use of whey protein hydrolysates, could help avoid these defects. On the other hand, the change of process parameters such as $\mathrm{pH}$ and fermentation temperature, as well as the moment of addition of the starter culture, could improve the growth of the strain L. rhamnosus LR35 and the stability of the strain L. acidophilus LA5, which both remain low. 


\section{ACKNOWLEDGMENTS}

Author M. N. Oliveira wishes to thank Fundação de Amparo à Pesquisa do Estado de São Paulo (FAPESP) for financial support.

\section{REFERENCES}

Beal, C., J. Skokanova, E. Latrille, N. Martin, and G. Corrieu. 1999. Combined effects of culture conditions and storage time on acidification and viscosity of stirred yogurt. J. Dairy Sci. 82:673-681.

Corrieu, G., H. E. Spinnler, D. Picque, and Y. Jomier. 1988. Procédé de mise en évidence et de contrôle de l'activité acidifiante d'agents de fermentation dans des bains de fermentation et dispositif pour sa mise en œuvre. Institut National de la Recherche Agronomique, French Pat. Num. 8814456.

Dave, R. I., and N. P. Shah. 1998. Ingredient supplementation effects on viability of probiotic bacteria in yogurt. J. Dairy Sci. 81:2804-816.

Dave, R. I., and N. P. Shah. 1997. Viability of yoghurt and probiotic bacteria in yogurts made from commercial starter cultures. Int. Dairy J. 7:31-41.

Donnet-Hughes, A., F. Rochat, P. Serrant, J. M. Aseschlimann, and E. J. Schiffrin. 1999. Modulation of nonspecific mechanisms of defense by lactic acid bacteria: effective dose. J. Dairy Sci. 82:863-869.

Fonden, R., G. Mogensen, R. Tanaka, and S. Salminen. 2000. Culturecontaining dairy products: Effects on intestinal microflora, human nutrition and health. Current knowledge and future perspectives. Bull. Int. Dairy Federation 352:1-30.

Gardini, F., R. Lanciotti, M. E. Guerzoni, and S. Torriani. 1999. Evaluation of aroma production and survival of Streptococcus thermophilus, Lactobacillus delbrueckii subsp bulgaricus and Lactobacillus acidophilus in fermented milks. Int. Dairy J. 9:125-134.

Godward, G., K. Sultana, K. Kailasapathy, P. Peiris, R. Arumugaswamy, and N. Reynolds. 2000. The importance of strain selection on the viability and survival of probiotic bacteria in dairy foods. Milchwissenschaft 55:441- 445.

Guarner, F., and G. J. Schaafsama. 1998. Probiotics. Int. J. Food Microbiol. 39:237-238.

IDF. 1995. Detection and enumeration of Lactobacillus acidophilus. Bull. IDF. 306:23-33.

Karagük-Yücer, Y., J. C. Wilson, and C. H. White. 2000. Formulations and processing of yogurt affect the microbial quality of carbonated yogurt. J. Dairy Sci. 84:543-550.

Kneifel, W., D. Jaros, and F. Erhard. 1993. Microflora and acidification properties of yogurt and yogurt-related products fermented with commercially available starter cultures. Int. J. Food Microbiol. 18:179-189.
Lankes, H., H. B. Ozer, and R. K. Robinson. 1998. The effect of elevated milk solids and incubation temperature on the physical properties of natural yogurt. Milchwissenschaft 53:510-513.

Lucey, J. A., and H. Singh. 1998. Formation and physical properties of acid milk gels: A review. Food Res. Int. 30:529-542.

Nighswonger, B. D., M. M. Brashears, and S. E. Gilliland. 1996. Viability of Lactobacillus acidophilus and Lactobacillus casei in fermented milk products during refrigerated storage. J. Dairy Sci. 79:212-219.

Oliveira, M. N., I. Sodini, F. Remeuf, and G. Corrieu. 2002. Effect of milk supplementation and culture composition on acidification, textural properties, and microbiological stability of fermented milks containing probiotic bacteria. Int. Dairy J.11:939-946.

Rajagopal, S. N., and W. E. Sandine. 1990. Associative growth and proteolysis of Streptococcus thermophilus and Lactobacillus bulgaricus in skim milk. J. Dairy Sci. 73:894-899.

Rohm, H., and W. Schmidt. 1993. Influence of dry matter fortification on flow properties of yogurt. 1. Evaluation of flow curves. Milchwissenschaft 48:556-560.

Rybka, S., and G. H. Fleet. 1997. Populations of Lactobacillus delbrueckii ssp bulgaricus, Streptococcus thermophilus, Lactobacillus acidophilus and Bifidobacterium species in Australian yogurts. Food Aus. 49:471-475.

Saxelin, M., B. Grenov, U. Svensson, R. Fonden, R. Reniero, and T. MattilaSandholm. 1999. The technology of probiotics. Trends Food Sci. Technol. 10:387-392.

Saxena, S. N., B. K. Mital , and S. K. Garg. 1994. Effect of casitone and fructose on the growth of Lactobacillus acidophilus and its survival during storage. Int. J. Food Microbiol. 21:271-272.

Shah, N. P. 2000. Probiotic bacteria: Selective enumeration and survival in dairy foods. J. Dairy Sci. 83:894-907.

Shah, N. P., and R. R. Ravula. 2000. Influence of water activity on fermentation, organic acids production and viability of yogurt and probiotic bacteria. Aust. J. Dairy Technol. 55:127-131.

Shihata, A., and N. P. Shah. 2000. Proteolytic profiles of yogurt and probiotic bacteria. Int. Dairy J. 10:401-408.

Shin, H. S., J. H. Lee, J. J. Pestka, and Z. Ustunol. 2000. Growth and viability of commercial Bifidobacterium ssp in skim milk containing oligosaccharides and inulin. J. Food Sci. 65:884-887.

Sodini, I., G. Corrieu, and E. Latrille. 2000. Identification of interacting mixed cultures of lactic acid bacteria by their exclusion from a model predicting the acidifying activity of non-interacting mixed cultures. Applied Microbiol. and Biotechnol. 54:715-718.

Van Marle, M., and P. Zoon. 1995. Permeability and rheological properties of microbially and chemically acidified skim milk gels. Neth. Milk Dairy J. 49:47-65.

Vanderhoof, J. A., and R. J. Young. 1998. Use of probiotics in childhood gastrointestinal disorders. J. Pediatric Gastroenterol. and Nutrition 27:323-332.

Vinderola, C. G., N. Bailo, and J. A. Reinhemier. 2000a. Survival of probiotic microflora in Argentinian yogurts during refrigerated storage. Food Res. Int. 33:97-102.

Vinderola, C. G., M. Gueimonde, T. Delgado, J. A. Reinheimer, and C. G. de los Reyes-Gavilan. 2000b. Characteristics of carbonated fermented milk and survival of probiotic bacteria. Int. Dairy J. $10: 213-220$ 